\title{
RETRACTED ARTICLE: Probability of Being 'Multidimensional' Poor
}

\author{
Kubilay Kaptan ${ }^{1}$
}

Accepted: 14 March 2016/Published online: 5 April 2016

(C) Springer Science+Business Media Dordrecht 2016

The Editor-in-Chief of Social Indicators Research retracts this article (Mar 2016) per the Committee on Publication Ethics (COPE) guidelines on plagiarism, due to unattributed use of substantial portions of text from the following article, by Dewilde, Individual and institutional determinants of multidimensional poverty: A European comparison (Social Indicators Research 2008; 86:233-256; Springer, DOI: 10.1007/s11205-007-9106-6). The Editor-in-Chief takes issues of research and publication misconduct seriously in order to preserve the integrity of the academic record. Our apologies are extended to the readers that this issue was not discovered before publication.

The online version of this article contains the full text of the retracted article as electronic supplementary material.

Electronic supplementary material The online version of this article (doi:10.1007/s11205-016-1296-3) contains supplementary material, which is available to authorized users.

Kubilay Kaptan

kaptankubilay@gmail.com

1 International Blue Crescent Relief and Development Foundation, Center for Humanitarian Studies, Istanbul, Turkey 